\title{
A Sensitive Remote Experiment for Small Scale Groundwater Flow Problems
}

\author{
http://dx.doi.org/10.3991/ijoe.v9iS8.3397 \\ J.C. Marques \\ Universidade do Porto, Porto, Portugal
}

\begin{abstract}
Seepage or groundwater flow is an important topic in Civil and Mining Engineering curricula. A laboratory setup has been developed for small scale studies of seepage in embankment dams and other geotechnical structures for use in the context of a Soil Mechanics course. Numerical simulations have been prepared as a complement to the experimental setup. Remote access to the equipment has been made available via an IP camera. Student feedback about this sensitive remote experiment has been very positive.
\end{abstract}

Index Terms-Experimental setup, groundwater flow, numerical simulation, remote experiment.

\section{INTRODUCTION}

For many people the word "dam" is associated with very large concrete structures whose purpose is to create a reservoir that can be used for electricity production, water supply or irrigation. This is particularly the case in Northern Portugal where the narrow canyons with steep granite banks of the Douro River provide excellent foundation conditions for concrete arch dams.

Nevertheless the predominant types are earth and rockfill dams which represent $63 \%$ and $8 \%$, respectively, of all reported dams in the world, according to the International Commission on Large Dams [1]. Nurek, an earth dam in Tajikistan, with $300 \mathrm{~m}$ height, is the world second highest dam. Rogun, an earth and rockfill dam under construction also in Tajikistan, will reach $335 \mathrm{~m}$.

In the design of embankment dams, which is a generic designation for earth and rockfill dams, special attention must be given to seepage or groundwater flow phenomena, through both the foundation and the body of the dam.

The major concern is to adequately control and prevent erosion processes involving transport of soil particles due to seepage forces. If such phenomena go undetected major disasters may occur, as illustrated by the 1976 collapse of Teton Dam (USA) [2, 3].

Seepage is therefore an important item in the Soil Mechanics courses for Civil and Mining Engineering students. The development and use of didactic experimental equipment for course support has been described by various sources $[4,5]$.

\section{DeVelopment OF SEePToOL}

In order to illustrate the main design strategies for seepage control in embankment dams, while also providing visualization of groundwater flow phenomena, SEEPTOOL, an apparatus for small scale modeling of seepage in this kind of engineering structures, has been developed and extensively tested in the context of MSc thesis work [6-7] (Fig.1). Experimental activity has been complemented by numerical simulation using the finite element method (Fig.2).

\section{Use OF SEePTool AS A TeAching AID}

SEEPTOOL is now actively used as a teaching aid in the Soil Mechanics course at FEUP. It provides excellent conditions for live demonstration of the reservoir filling procedure, the visualization of flow line development by injection of colour fluid and the measurement of head loss along the seepage path provided by the piezometers in the back vertical wall.

Various cross section configurations have been tested and each one of them when completed can be used over and over. It is only convenient to renew the water from time to time, once it starts being coloured by the fluid injected for visualization of flow lines.

An IP camera makes video image available for remote use in the lecture theatre as well as for remote demos at request anywhere else via internet (Fig.3).

Remote access to the setup via the IP camera provides additional flexibility to this instructional tool for seepage studies.

Student response to this sensitive remote experiment has been very positive [8].

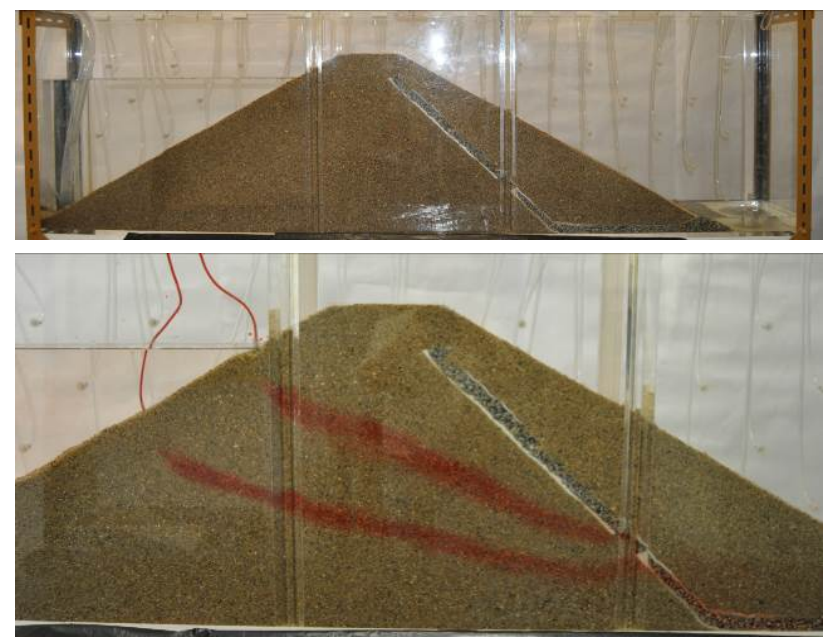

Figure 1. Small scale earth dam with a chimney drain (top); flow lines obtained with injection of color fluid (bottom).

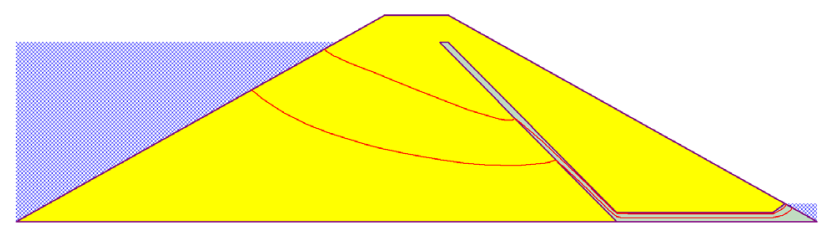

Figure 2. Flow lines obtained by means of a finite element numerical simulation of a small scale earth dam with a chimney drain. 


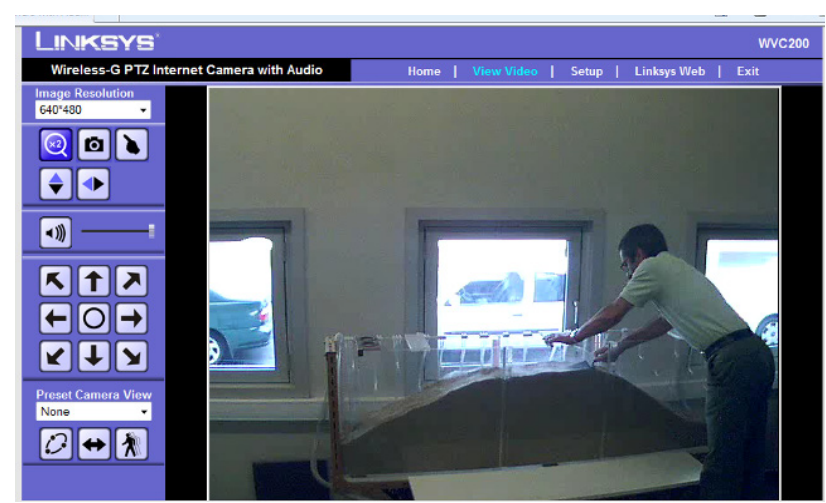

Figure 3. User interface of the IP camera as viewed from the remote user.

\section{STUDENT FEEDBACK}

Once the development of the SEEPTOOL setup has been finalized and became available for live or remote demos, it has been very welcome by students and has attracted a lot of attention and interest.

In order to assess the instructional value of the sensitive remote experiment available for demos at request based on SEEPTOOL, a survey is conducted in the $1^{\text {st }}$ semester, when the topic of groundwater flow is covered in the Soil Mechanics course for Civil and Mining Engineering students.

In the current academic year a sample of 137 students contributed to the survey from a universe of 281 .

Considering the particular focus of the present work, the following four questions were selected from the survey questionnaire, in order to assess the added value specifically brought in by the sensitive remote experiment.

Question 1 - How much does the visualization of flow lines contribute to the perception of the groundwater flow phenomenon?

Question 2 - In what way does the evolution of the pressure head in the piezometers contribute to the understanding of the head loss phenomenon?

Question 3 - How much does this remote sensitive experiment contributes to the understanding of the physical aspects of groundwater flow?

Question 4 - How do you rate the interest of this type of remote tool?

Students were asked to reply to each question by writing an $\mathrm{X}$ on a straight line whose range goes from "not at all" up to "very much". The results were analysed by dividing the line segment in ten equal intervals numbered from 1 to 10 and collecting the number of X marks located in each interval. The statistics are reported in Table I.

The survey results are graphically presented in Figure 4 which shows in percentage terms the distribution of the replies across the ten intervals for each of the four questions.

The survey clearly shows the very positive impact of the SEEPTOOL setup in its multiple dimensions.

\section{Current Developments}

It is possible to replicate in SEEPTOOL various seepage control strategies currently used in real embankment dams, e.g., toe drain, drainage blanket and clay core (Figure 5).
TABLE I.

SURVEY RESULTS

\begin{tabular}{|c|c|c|c|c|}
\cline { 2 - 5 } \multicolumn{1}{c|}{} & Q.1 & Q.2 & Q.3 & Q.4 \\
\hline $\mathbf{1}$ & 0 & 0 & 2 & 0 \\
\hline $\mathbf{2}$ & 0 & 0 & 1 & 0 \\
\hline $\mathbf{3}$ & 2 & 0 & 0 & 0 \\
\hline $\mathbf{4}$ & 2 & 1 & 1 & 3 \\
\hline $\mathbf{5}$ & 5 & 10 & 7 & 5 \\
\hline $\mathbf{6}$ & 5 & 6 & 4 & 6 \\
\hline $\mathbf{7}$ & 11 & 10 & 15 & 12 \\
\hline $\mathbf{8}$ & 19 & 26 & 10 & 12 \\
\hline $\mathbf{9}$ & 29 & 24 & 32 & 26 \\
\hline $\mathbf{1 0}$ & 64 & 60 & 65 & 73 \\
\hline
\end{tabular}
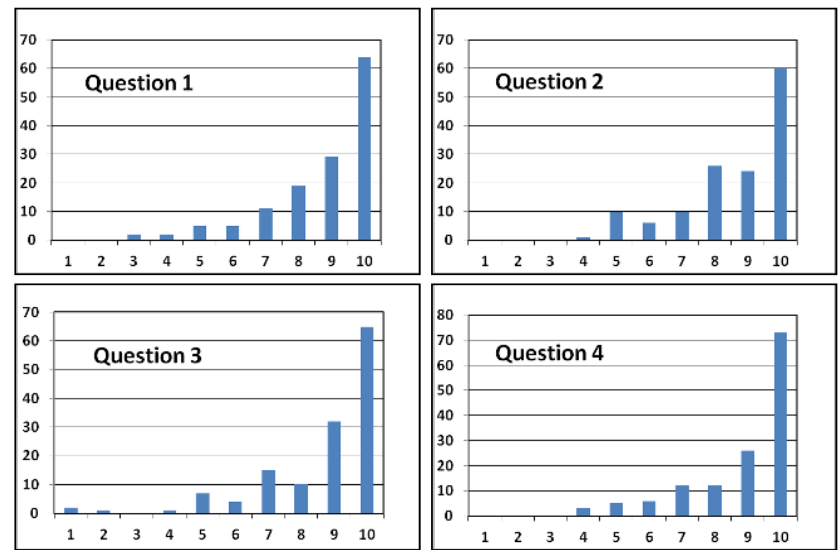

Figure 4. Results of the student survey in terms of percentage.

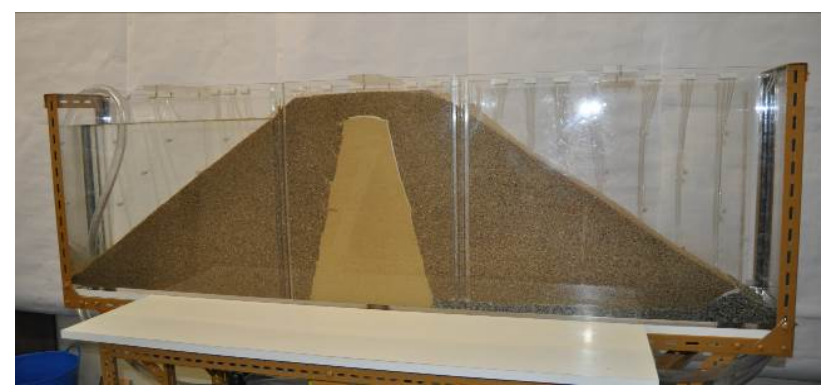

Figure 5. Small scale model of earth dam with central core, drainage blanket and toe drain.

But any change in the configuration of the cross section of the small scale dam for inclusion of a different seepage control device involves many hours of hard physical work, for removing some $200 \mathrm{~kg}$ of granular soil, cleaning the whole apparatus and starting all over again with a new cross section layout.

Therefore further developments of SEEPTOOL are now being conducted in a number of complementary directions. Video recordings are being made of several alternative configurations, each highlighting either a particular seepage control strategy or a combination of several of them.

This will provide raw material for improving an interactive video [9] that makes available an extensive coverage of the topic of seepage control in embankment dams and in other related geotechnical structures, such as cofferdams. 


\section{SHORT PAPER}

\section{A SENSITIVE REMOTE EXPERIMENT FOR SMALl SCALE GROUNDWATER FlOW PROBLEMS}

An augmented reality tool is also being prepared for offering to students a complementary type of virtual demo taking advantage of a certain degree of immersion achieved by projecting on the setup sequential images of each experiment, combined with plots from numerical simulations.

This will make available a wider range of demos, thus making the most of the long hours of preparation and maintenance required for setting up each specific cross section configuration of the small scale dam models, while allowing students to revisit and review them with a simple tablet.

\section{ACKNOWLEDGMENT}

Many thanks are due to all the colleagues and students who have contributed to the work reported in this paper. The financial support granted to the SEEPTOOL project by the University of Porto is gratefully acknowledged.

The present work is in line with tasks related with the Internet of Things within PEst-OE/EME/LA0022/2013, FCT.

\section{REFERENCES}

[1] http://www.icoldcigb.net/GB/World register/general synthesis.asp (accessed November 2013).

[2] http://www.history.com/shows/modernmarvels/videos/engineering-disasters-teton-dam\#engineeringdisasters-teton-dam (accessed November 2013).
[3] http://www.youtube.com/watch?v=KEdM6Ys6spA (accessed November 2013).

[4] R. Cardoso, R.C. Gomes, J.A. Santos, V. Sena Costa, and J.P Caetano, "Novos equipamentos didácticos no ensino da Mecânica dos Solos," $10^{\circ}$ Congresso Nacional de Geotecnia, Vol.2-33, Lisboa, 2006.

[5] T. Santana, P. Lamas, "Modelos físico simples de apoio ao ensino de Geotecnia," $10^{\circ}$ Congresso Nacional de Geotecnia, Vol.2-34, Lisboa, 2006.

[6] C.R. Ferreira, "Development of a Laboratory Equipment for Small Scale Study of Seepage Problems," Master Thesis in Civil Engineering (in Portuguese), FEUP, Porto, 2008, 125p.

[7] M.S.P. Unas, "Experimental and Numerical Small Scale Study of Seepage Problems," Master Thesis in Civil Engineering," (in Portuguese), FEUP, Porto, 2010, 190p.

[8] J.C. Marques, J. Quintela, M.T. Restivo, V.M Trigo, "Engineering, Concepts and Video Clips," International Journal of Engineering Pedagogy (iJEP), vol.3, Special Issue TaT 2012, pp.2225, 2013.

[9] J.C. Marques, M.T. Restivo, T. Santos, and A. Cardoso, "An interactive video for groundwater flow," IEEEXplore, DOI $\underline{10.1109 / \text { ICL.2013.6644712 }}$

\section{AUTHOR}

J. C. Marques is with IDMEC-FEUP and Faculty of Engineering, University of Porto, Porto, Portugal (e-mail: jmarques@fe.up.pt).

This article is an extended and modified version of a paper presented at the International Conference exp.at'13, held 18-20 September 2013, in Coimbra, Portugal. Submitted 18 November 2013. Published as resubmitted by the authors 04 December 2013. 